\title{
Mapping current research trends on anterior cruciate ligament injury risk against the existing evidence: In vivo biomechanical risk factors - A Letter to the Editor
}

\author{
Timothy E. Hewett and \\ Mayo Clinic, 200 First Street SW; RO_Gu_01_28BIOM; Rochester, MN 55905 United States \\ Gregory D. Myer \\ Cincinnati Children's Hospital, 3333 Burnet Avenue MLC 10001 Cincinnati,OH 45229-3039, \\ United States
}

\section{Keywords}

Mapping; Ligament; Biomechanical

Dear Editor of Clinical Biomechanics:

"Mapping current research trends on anterior cruciate ligament injury risk against the existing evidence: In vivo biomechanical risk factors - A Letter to the Editor".

We read with interest the recent study published in Clinical Biomechanics entitled "Mapping current research trends on anterior cruciate ligament injury risk against the existing evidence: In vivo biomechanical risk factors" by Sharir et al. The stated aims of the study were to "firstly, to systematically review the in vivo biomechanical literature that has identified risk factors for non-contact ACL injury during dynamic sports tasks and secondly, to critically evaluate the research trends from retrospective and associative studies investigating non-contact ACL injury risk."

We congratulate the authors for performing this timely and important Systematic Review. The authors' concluded, "Our search revealed one prospective cohort study which aimed to determine how in vivo biomechanics can serve as a predictor of noncontact ACL injury (Hewett et al., 2005). This study found that female athletes with increased dynamic knee abduction angle and with a high knee abduction moment are risk factors for ACL injury, albeit in a small sample of injuries. Many associative studies are based on these results alone and are therefore at risk of task and parameter bias. Though a reasonably large number of level 2 and 3 evidence studies are available, more prospective cohort studies are needed to drive on-going work with the purpose of developing prevention programmes and clinical interventions. Generating a critical mass of high quality level 1 evidence should therefore be the priority for research to advance the understanding of in vivo biomechanical risk factors for non-contact ACL injury." However, the suggested critical mass may already be available. 
In the current systematic review (Section 4.1), the authors' cite identified abstracts of relevance. They state "Abstracts from two additional prospective cohort studies were presented at the IOC 2014 World Conference Prevention of Injury \& Illness in Sport, Monaco, France. The first study (Kristianslund et al., 2014) collected prospective DVJ data from 708 Norwegian elite female football and handball players and observed 38 non-contact ACL injuries. This has recently been published (Krosshaug et al., 2016) with 42 non-contact ACL injuries registered and KAM, KAA, knee flexion angle and peak GRF were reported not to predict ACL injury.” Regarding the aforementioned Kristianslund abstract and Krosshaug manuscripts, prospective measures of medial knee collapse during the DVJ DID identify ACL injury risk in their cohort of athletes. Importantly, these data may be the strongest evidence yet published in the literature to confirm that medial knee collapse (highly correlated to KAA and KAM) is a strong identifier of ACL injury risk as this metric was still sensitive even after up to four years passing from screening date to injury. Even more salient, a large percentage of cohort had undergone repeated bouts of neuromuscular training designed to correct dynamic valgus. The potential for screening to differentiate increased risk after up to four years of sport and injury prevention training is noteworthy and important result of this investigation.

Further adding the 'critical mass' of evidence, the authors highlight a second study abstract presented at the IOC meeting. "The second study involved US military cadets (Padua, 2014), where 117 ACL injuries were observed in males and females from a cohort of 5758 cadets. They also found that KAM and KAA did not predict ACL injury but they did observe increased hip adduction and increased internal tibial rotation at contact in those who sustained an ACL injury." Understandably, the authors may have missed the multiple presentations and published abstracts that reported that KAA DID identify ACL injury in the largest cohort (AOSSM, 2009, NATA, 2009, Military Medicine, 2008) of prospective ACL injury data to date. This important work from Padua and colleagues highlights the potential of prospective dynamic valgus screening measures to identify increased ACL injury risk generalizable to military populations.

While the acknowledgment of the high level of evidence of prior work is appreciated, we challenge these authors to recognize the important work of others which deserves recognition and highlight the consistent association of prospective dynamic valgus measures measured during the drop vertical jump to identify increased ACL injury risk.

Sincerely,

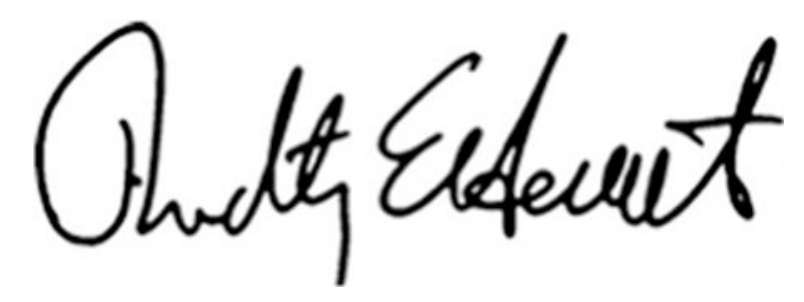

Timothy Hewett, PhD. 
Mayo Clinic.

Consultant, Orthopedic Surgery.

Director, Biomechanics, Sports Medicine Research.

Professor of Orthopedic Surgery, Physical Medicine \& Rehabilitation.

Physiology \& Biomedical Engineering.

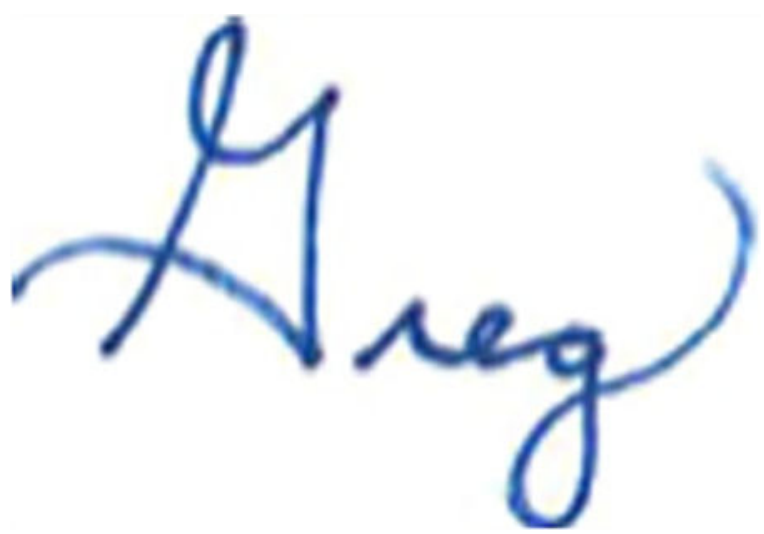

Gregory D. Myer, PhD, FACSM, CSCS*D.

Director, Research and The Human Performance Laboratory.

Division of Sports Medicine I Cincinnati Children's Hospital Medical Center.

3333 Burnet Avenue, MLC 10001, Cincinnati, OH 45229.

\section{References}

Hewett TE, Myer GD, Ford KR, Heidt RS Jr., Colosimo AJ, McLean SG, et al., 2005 Biomechanical measures of neuromuscular control and valgus loading of the knee predict anterior cruciate ligament injury risk in female athletes: a prospective study. Am. J. Sports Med 33 (4), 492-501. 10.1177/0363546504269591. [PubMed: 15722287]

Krosshaug T, Steffen K, Kristianslund E, Nilstad A, Mok KM, Myklebust G, et al., 2016 The vertical drop jump is a poor screening test for ACL injuries in female elite soccer and handball players: a prospective cohort study of 710 athletes. Am. J. Sports Med 10.1177/0363546515625048.

Kristianslund E, Krosshaug T, van den Bogert AJ, 2014 Effect of low pass filtering on joint moments from inverse dynamics: implications for injury prevention. J. Biomech 45 (4), 666-671.

Military Medicine, 62008 vol. 173, 515-522 No. 6. [PubMed: 18595411]

Padua DA, Marshall SW, Beutler AI, Garrett WE, 2009 Prospective cohort study of biomechanical risk factors of ACL injury: The JUMP-ACL Study American Orthopaedic Society of Sports Medicine Annual Meeting. 710 Keystone, CO, pp. 393-395.

Padua, et al., 2009 JUMP-ACL STUDY Report. National Athletic Trainer's Association. San Antonio TX.

Padua DA (Ed.), 2014 The Jump ACL Study — Drop Jump Task can Predict ACL Injuries in US Military Cadets IOC World Conference Prevention of Injury \& Illness in Sport (Monaco). 